\title{
A insustentabilidade social violadora de direitos humanos no modelo de controle penal e a privação das capacitações (capabilities)
}

\section{The human rights violatory social unsustainability in the criminal control model and the deprivation of capabilities}

\author{
Felipe da Veiga Dias* \\ Neuro José Zambam* \\ Alexandre Marques Silveira ${ }^{* *+*}$
}

\section{Resumo}

\begin{abstract}
Considerando a insustentabilidade do controle penal contemporâneo e a banalização do sistema punitivo, este artigo tem como objetivo compreender as contribuições de Amartya Sen para a sua avaliação crítica e superação, visando à efetivação dos direitos e garantias básicas dos seres humanos, ou seja, a promoção das capacitações (capabilities). 0 método de investigação é o dedutivo, com procedimento monográfico e técnica de pesquisa da documentação indireta. Concluiu-se, conforme Sen, que as soluções para os problemas dependem de opções políticas e investimentos nas necessidades básicas da população, especificamente saúde, educação e projetos habitacionais, diminuindo, assim, as desigualdades, a violência e os preconceitos, alternativas ao insustentável sistema punitivo e seletivo em vigor.
\end{abstract}

Palavras chave: Controle social. Desigualdades. Capacitações (capabilities). Seletividade penal. Amartya Sen.

\section{Abstract}

\begin{abstract}
Considering the unsustainability of contemporary criminal control and the banalization of the punitive system, this article aims to understand the contributions of Amartya Sen for its critical evaluation and overcoming, aiming at the realization of the basic rights and guarantees of human beings, that is, the promotion of capabilities. The research method is the deductive, along with the monographic procedure and the research technique of indirect documentation. It was concluded, according to Sen, that solutions to problems depend on political options and investments in the basic needs of the population, specifically health, education and housing projects, thus reducing inequalities, violence and prejudice, alternative to the unsustainable punitive selective system in force.
\end{abstract}

Keywords: Social control. Inequalities. Capabilities. Criminal selectivity. Amartya Sen.

\section{Introdução}

Mesmo com a maximização da criminalização e expansão de novos tipos penais, países marginalizados ou periféricos, como o Brasil, ainda apresentam um contexto de impunidades inaceitáveis moral e juridicamente. O poder estatal preocupa-se somente em combater aquela fração da sociedade que pertence às classes

Doutor em Direito pela Universidade de Santa Cruz do Sul (UNISC), com período de Doutorado Sanduíche na Universidad de Sevilla (Espanha). Professor do Programa de Pós-Graduação em Direito da Faculdade Meridional (IMED) - Mestrado. Professor do curso de Direito da Faculdade Meridional (IMED) - Passo Fundo - RS. Brasil. Coordenador do Grupo de Pesquisa "Criminologia, Violência e Sustentabilidade Social". Advogado. Passo Fundo - RS - Brasil. E-mail: felipevdias@gmail.com.

Doutor em Filosofia pela PUCRS. Professor do Programa de Pós-Graduação em Direito da Faculdade Meridional (Imed) - Mestrado. Professor do curso de Direito (Graduação e Especialização) da Faculdade Meridional (Imed) de Passo Fundo. Membro do Grupo de Trabalho, Ética e Cidadania da Associação Nacional dos Programas de Pós-Graduação em Filosofia (Anpof). Pesquisador da Faculdade Meridional. Coordenador do Grupo de Pesquisa: Multiculturalismo, minorias, espaço público e sustentabilidade. Líder do Grupo de Estudo, Multiculturalismo e Pluralismo Jurídico. Líder do Centro Brasileiro de Pesquisa sobre Amartya Sen: Interfaces com Direito, Políticas de Desenvolvimento e Democracia. Passo Fundo - RS- Brasil. E-mail: nzambam@imed.edu.br.

*** Mestre em Direito da Faculdade Meridional de Passo Fundo - IMED, com bolsa na modalidade Taxa PROSUP/CAPES. Especialista em Direito Penal pela Faculdade de Direito Prof. Damásio de Jesus. Membro do grupo de pesquisa Criminologia, Violência e Sustentabilidade Social (IMED), coordenado pelo Prof. Dr. Felipe da Veiga Dias. Graduado em Direito pela Faculdade Metodista de Santa Maria-FAMES. Passo Fundo - RS- Brasil. E-mail: alexandremarquessilveira@gmail.com. 
sociais que possuem insuficiência de recursos sociais para a construção de uma cidadania digna e, dessa forma, aprofundam ou permanecem como vulneráveis e suscetíveis à criminalidade. Portanto, o poder punitivo continua sendo brando com aqueles que pertencem às classes sociais dominantes, que tem maior poder aquisitivo e que fazem parte do controle social formal e informal.

Dessa maneira, genocídios são praticados indiretamente pelo Estado, seja pelas omissões e negligências, seja por meio de ações reiteradas de violência. Essas práticas ficam impunes, uma vez que o poder estatal é o grande operador do sistema penal. Logo, a aplicabilidade dos mecanismos punitivos tornou-se algo habitual para os grupos sociais mais pobres e marginalizados pelo Estado, o que ocasiona a privação das capacitações (capabilities) desses grupos impedindo que exista o exercício da liberdade e as condições para o seu desenvolvimento.

Nessa perspectiva, este trabalho tem como objetivo analisar as contribuições de Sen $^{1}$ sobre as privações das capacidades dos indivíduos na contemporaneidade brasileira, inclusive as condições para a superação da banalização da dignidade humana e do atual sistema punitivo. Assim, a questão que orientará a pesquisa sobre o tema é: quais são as possíveis soluções para a superação da insustentabilidade social do controle estatal penal a partir de Amartya Sen?

A arquitetura desta apresentação, inicialmente, apresenta as noções básicas da sustentabilidade social, tendo em vista que suas bases servem como referência à leitura sobre a intervenção estatal no campo penal, bem como define espectros mais abrangentes sobre os danos provocados à população. Posteriormente, examina-se o controle social penal contemporâneo à privação das capacitações (capabilities), e as exclusões e desigualdades que este ocasiona. Em destaque estão os componentes criminológicos, a fim de propiciar a compreensão do estado da arte punitiva no país e dos efeitos gerados sobre os mais vulneráveis.

Finalmente, trata-se sobre o sistema punitivo como um mecanismo de privação das capacitações (capabilities) dos mais pobres, quando serão verificadas as contribuições de Sen para uma possível solução. O autor, com sua abordagem centrada no valor da pessoa e nas condições para o exercício da cidadania, busca combinar e adicionar fatores de crítica à postura violatória do Estado brasileiro. O método de abordagem que servirá de referência para a análise das ideias, informações e resultados desta pesquisa é o método dedutivo, que parte de observações gerais para chegar a um objetivo de pesquisa específico. Quanto ao método de procedimento, será o monográfico, contemplando obras de referência sobre o tema, e a técnica de pesquisa da documentação indireta.

\section{2 À guisa de preliminar: a sustentabilidade social e as bases ético-sociais da mudança}

A pesquisa ora proposta poderia partir dos pressupostos criminológicos que desconstroem o controle penal contemporâneo, no entanto, visando uma abordagem mais ampla, crítica e construtiva da rearticulação ético-social, opta-se pela combinação entre os pressupostos críticos criminológicos e a concepção da sustentabilidade. Essa combinação encontra-se alinhada à visão mais abrangente de sustentabilidade, capacitando-a não apenas como elemento de contestação dos problemas ambientais, mas igualmente para contestar questões relativas à degradação econômica, social, das instituições, dentre outras vertentes.

Alude-se isto partindo da visão de Elkington (1998) e seu modelo de triple bottom line, o qual define que, sem a combinação de fatores econômicos e sociais, não se poderia pensar os objetivos da sustentabilidade ambiental, ou seja, a partir de sua construção, esses três conteúdos passam a ser vistos em interconexão. Atualmente, existem modelos mais amplos e que inserem novas camadas a tal pensamento (tendo em vista que, segundo alguns autores, esse modelo deixaria aspectos importantes de fora de sua abordagem) (NASCIMENTO, 2012, p. 56), porém aqui ele é suficiente para enaltecer o fato de que os desequilíbrios nas mais diversas áreas possuem o potencial de tornar um ambiente insustentável.

Renomado professor de economia e filosofia de Harvard. Ganhador do prêmio Nobel de economia (1998). Conhecido por contribuir para a teoria justiça social com seus trabalhos sobre mediação de bem-estar e pobreza, capacidades individuais e liberdade. Disponível em: https://www. nobelprize.org/nobel_prizes/economic-sciences/laureates/1998/sen-facts.html. Acesso em: 25 jan. 2018. 
A compreensão conceitual de Mckenzie (2004, p. 6, tradução nossa) demonstra a ocorrência da sustentabilidade social quando "os processos, sistemas, estruturas e relacionamentos formais e informais apoiam ativamente a capacidade das gerações atuais e futuras de criar comunidades saudáveis e habitáveis". Dessa maneira, as comunidades socialmente sustentáveis são "equitativas, diversas, conectadas e democráticas e proporcionam uma boa qualidade de vida".

Assim, ao atentar para a sustentabilidade social, embora inexista um conceito estritamente fechado, haja vista a complexidade relacionada ao tema, ainda se encontra de forma contumaz a sua relação com a melhoria nas condições de vida da população e a busca pela justiça social. De tal modo que, ao se defrontar com tais objetivos, percebe-se que um sistema penal precisa estar alinhado com os pressupostos jurídico-constitucionais, havendo, portanto, a exigência de garantir e proteger os direitos humanos. Mas, ao mesmo tempo, deve obedecer a parâmetros de sustentabilidade,$^{2}$ tanto em sentido material quanto ético.

Os problemas fáticos advindos do sistema penal nacional são reconhecidos e melhor abordados na segunda etapa deste estudo, mas as nuances circundantes já restam denunciadas de forma concomitante, seja pela criminologia, seja pela sustentabilidade social. Assevera essa afirmativa o fato de que as desigualdades sociais geradas no atual sistema econômico, ocasionando efeitos como pobreza e problemas nas áreas de empregabilidade, habitação, saúde e educação, os quais são contestados no nível de sustentabilidade social (BOFF, 2016, p. 150), são os mesmos fatores utilizados para escolha seletiva dos alvos a serem punidos pelo sistema de controle social estatal.

Apesar dos dados sobre a concentração de renda, o enriquecimento de poucos e a desigualdade no mundo serem alarmantes, durante muito tempo optou-se pela negação dessas questões, a fim de ocultar as falhas do modelo econômico capitalista (BOFF, 2016, p. 151). Significa dizer que o projeto da modernidade, baseado no desenvolvimento para melhoria das condições gerais de vida, não se concretiza, e pior, conclue-seconclui-se que, se não for repensado o abismo entre ricos e pobres, somente será alargado (OXFAM, 2018).

Outrossim, merece registro que as ideias de desigualdade e de pobreza geradas no atual perfil social devem ser tomadas em sentido amplo e complexo, ou seja, conforme explica Morin (2015, p. 148), a pobreza é mais do que a ausência de condições de subsistência, sendo constituída também pelas carências relacionais, de formação (culturais) e de condições de vida. É importante considerar a pobreza "como um enfraquecimento das potencialidades de escolha e de ação e, mais profundamente, como a ausência de controle sobre sua condição e seu destino". Com igual amplitude, Sen (2000, p. 109) afirma que "a pobreza deve ser vista como privação das capacidades básicas em vez de meramente, como baixo nível de renda, que é o critério tradicional de identificação da pobreza". As desigualdades estão na origem de graves dilemas sociais, como a classificação de pessoas e outras formas de exclusão. O exercício da liberdade e o desenvolvimento das capacitações (capabilities) dependem do equilíbrio social e das condições que as pessoas têm para organizar a sua vida e fazer escolhas importantes.

A preocupação com o crescimento da desigualdade se dá, prioritariamente, pelos aspectos da qualidade de vida humana na Terra, mas reverberam no tema do controle social, visto que a ausência dessas mesmas condições de vida posiciona um alvo sobre indivíduos vulneráveis, conforme se pode verificar na atuação punitiva do Estado.

Posto isso, a tônica da sustentabilidade social orienta os rumos da humanidade para uma nova via, a qual deve priorizar uma complexidade de fatores (MORIN, 2015, p. 38-39 e ss.), dentre os quais estão as relações individuais, sociais, a ocupação dos espaços e a necessidade de políticas públicas, além do atendimento às necessidades básicas (COLANTONIO, 2009, p. 9).

Nesse sentido, quando se fala em projetar caminhos diferentes para os seres humanos na Terra, não raras vezes, as metas buscam as modificações nas relações humanas e com o próprio planeta, ou

Para uma compreensão mais alargada do tema sugerimos. Disponível em: https://www1.folha.uol.com.br/folha/ciencia/ult306u11316.shtml. Acesso em: 15 set. 2018 . 
nas formas de atuação econômica (revisão do modelo de desenvolvimento/crescimento), e igualmente se atenta a elementos éticos essenciais a tais modificações. Essa alusão remete às características modernas da sociedade contemporânea, que se ampara no individualismo, no egoísmo e gera a frustração em uma sociedade voltada ao consumo irrestrito, motivando projetos alternativos, como o de Latouche (2011, p. 11-12) e a sua abundância frugal.

A inconformidade ética que impõe a crítica social também recai sobre o Estado e a forma de tratamento coercitivo de pessoas. Isto porque o denunciar da deslegitimidade de um sistema penal que não atua em consonância com seus parâmetros já é algo fartamente estabelecido na doutrina criminológica (ZAFFARONI, 1991, p. 16), mas ao aliar tais considerações a pressupostos éticos de orientação humana recrudesce-se a crítica aos problemas causados e às violações na atuação punitiva estatal.

Exemplifica tal alusão a adoção da alteridade, a qual não serve como um impedimento das violências realizadas, mas, sim, como conteúdo ético impositivo à rearticulação das instituições que regem o poder coercitivo estatal (SPERANDIO; AQUINO; CAMARGO, 2017, p. 500).

Contudo, independente da proposição disposta, todas convergem para a necessidade de reconhecimento do outro enquanto ser humano, que se reveste de toda a dignidade inerente a sua condição existencial, merecendo o devido cuidado (este termo é utilizado na acepção de Boff) (BOFF, 2015, p. 93). "O relacionamento com o Outro dissolve a minha totalidade (ou o mito da totalidade) e rompe para o infinito das significações quando se experimenta o estar-junto-com-o-Outro-no-mundo" (SPERANDIO; AQUINO; CAMARGO, 2017, p. 500).

O reconhecimento do outro enquanto ser humano parece algo óbvio, porém o sistema penal seletivo e excludente constrói sua narrativa para anular tal compreensão, o que impossibilita a aceitabilidade desse modelo de atuação segundo um projeto de sustentabilidade social. Antecedendo a abordagem de Sen (2000) sobre a responsabilidade do Estado na estruturação das sociedades de forma justa e sustentável, passa-se a apresentar os principais problemas e incongruências do atual sistema, para, assim, estruturar a combinação dos dois segmentos críticos de oposição ao atual controle social perpetrado pelo poder público no país.

\section{Controle social contemporâneo e a privação das capacitações (capabilities)}

Devido ao processo histórico nacional, ${ }^{3}$ à propagação da violência, à intolerância e aos altos índices de devastação do meio ambiente, o atual sistema punitivo brasileiro é algo consideravelmente insustentável, visto que a sociedade atual possui novas necessidades econômicas e educacionais, e ainda padece de desigualdades sociais, raciais e um meio de controle social com tendências seletivas e incriminadoras de grupos mais vulneráveis (ZAFFARONI; PIERANGELI, 2010, p. 58). Desse modo, o Estado Democrático de Direito passa por uma ampla inversão de garantias fundamentais constitucionais, já que se torna evidente a diferença entre as normativas positivadas e os objetivos punitivos não declarados.

No que tange aos atuais enfrentamentos sociais, o controle social do Estado acaba se limitando à "mera garantia de contenção do arbítrio" (GIAMBERARDINO, 2015, p. 177). O controle social traz como solução a expansão de inúmeros tipos penais, ampliando a criminalização de condutas. Como decorrência, há um grande número de encarceramentos, sendo que o país "atingiu, em junho de 2014, a lamentável marca de terceira maior população carcerária do mundo, sem, contudo, conter o crescimento da violência" (CASTRO, 2015, p. 11).

No primeiro semestre de 2016 foi realizado, pelo Ministério da Justiça e Segurança Pública, em conjunto com o Departamento Penitenciário Nacional (Depen), o Levantamento Nacional de Informações

Apenas como alusão às construções históricas perpetradas por meio do poder punitivo do Estado, menciona-se as violações institucionalizadas de racismo no Brasil, as quais foram legitimadas por meio de teorias ditas como "científicas" a fim de autorizar ações de exclusão social e criminalização da população negra. Essa postura teve contribuição significativa dos órgãos de controle social formal, sendo considerados verdadeiros crimes de Estado (CARVALHO; DUARTE, 2017, p. 25-38). 
Penitenciárias (Infopen), o qual apurou que: haviam 726.712 pessoas encarceradas no Brasil. Desse total, $5,8 \%$ eram mulheres, e o restante, homens. Dessas pessoas, $30 \%$ possui entre 18 e 24 anos; $25 \%$, entre 25 e 29 anos; 19\%, entre 30 e 34 anos e $26 \%$ possui 35 anos ou mais (INFOPEN, 2016).

Outros fatores que devem ser considerados e possuem relação direta com a temática abordada neste estudo são: do total de pessoas encarceradas no país, $51 \%$ tem o ensino médio incompleto; $64 \%$ são negros; $35 \%$, brancos e $1 \%$, amarelos e índios ${ }^{4}$ (INFOPEN, 2016). De toda população brasileira, $53 \%$ é negra e $46 \%$ é branca, sendo que negros são $63 \%$ dos pobres e $69 \%$ dos indigentes no Brasil (IBGE, 2017). Esses dados demonstram que a população negra no Brasil é a que mais sofre com a privação de suas capacitações (capabilities), tanto pelo controle social quanto pelo sistema carcerário, ou seja, pelo aporte estrutural do Estado e suas relações de poder e classe. Essa parte da população tem suas capacidades privadas em razão da falta de saneamento básico, de ensino, de oportunidades e devido à seletividade social (FLAUZINA, 2006, p. 38).

Nesse contexto de exclusão, discriminação e classificação de pessoas, que denuncia a insustentabilidade social, política, moral e jurídica, insere-se a abordagem das capacitações (capabilities) como alternativa ao atual sistema:

A capacidade [capability] de uma pessoa consiste nas combinações alternativas de funcionamentos cuja realização é factível para ela. Portanto, a capacidade é um tipo de liberdade: a liberdade substantiva de realizar combinações alternativas de funcionamentos (ou, menos formalmente expresso, a liberdade de ter estilos de vida diversos). Por exemplo, uma pessoa abastada que faz jejum pode ter a mesma realização de funcionamento quanto a comer ou nutrir-se que uma pessoa destituída, forçada a passar fome extrema, mas a primeira pessoa possui um 'conjunto capacitário' diferente da segunda (a primeira pode escolher comer bem e ser bem nutrida de um modo impossível para a segunda) (SEN, 2000, p. 95).

Portanto, o processo de expansão punitiva contemporânea e de encarceramento é apenas uma amostra das incongruências recentes de um sistema penal ilegítimo (por falta de racionalidade e coerência discursiva) e que direciona o controle social a atuações completamente distintas (realizando a chamada eficácia invertida) das suas funções declaradas (ANDRADE, 2012, p. 136).

A crítica deslegitimante dos sistemas penais no Brasil e na América Latina indica justamente a impossibilidade de que tais sistemas produzam censura, no sentido desejado. Há apenas violência de forma brutal e seletiva. Não é à toa, enfim, que mesmo com altíssimos índices de violência estatal e encarceramento em massa seja empiricamente constatável a percepção subjetiva de impunidade (GIAMBERARDINO, 2015, p. 82).

O discurso do atual modelo de intervenção punitiva demonstra um meio de controle social que conserva a violência ferindo direitos humanos, causando mais desigualdades sociais e exclusões: "[...] está claro que os assassinatos em massa, embora perpetrados pelo Estado, não são alheios a sua relação com o mercado e a sua lógica econômica" (BERNAL et al. 2014, p. 67, tradução nossa). O paradigma criado pela justiça criminal, qual seja, o retributivo, é voltado contra o agente infrator de maneira que este deve ser castigado por não seguir as regras de convivência, seguindo parâmetros de um direito penal máximo (JAKOBS; MELIÁ, 2012). Dessa maneira, cria-se, "claramente, uma divisão entre os indivíduos do bem e os indivíduos do mal que integram a sociedade, elimina o caráter de cidadão dos últimos" (CANTERJI, 2008, p. 53), causando mais exclusões, desigualdades e a privação das capacitações (capabilities).

Essa forma de atuação discriminatória e seletiva denota algo já evidenciado na perspectiva da insustentabilidade social desse sistema, pois, ao simplificar a realidade e os problemas enfrentados pela sociedade brasileira, trata de reduzir a complexidade dos fatos e travar uma luta binária entre bons e maus cidadãos. Isto perpetua um pensamento maniqueísta que busca fortalecer uma espécie de "nós contra o outro, 'outsiders antecipados', e a radical relação de exterioridade que os 'cidadãos de bem' mantém para com a problemática criminal, então fortemente moralizada" (ANDRADE, 2012, p. 166).

4 Em relação aos dados raciais demonstrados neste trabalho, todos se referem a pesquisas em que os indivíduos se autodeclararam negros, brancos, amarelos e indígenas. 
Posto isso, o sistema punitivo brasileiro está percorrendo um caminho que leva à inversão de um Estado Democrático de Direito, uma vez que, com todas essas mudanças advindas das ciências e técnicas humanas pós-modernas, houve uma grande e complexa alteração nas relações humanas (CANTERJI, 2008, p. 21), criando novos problemas que devem ser amparados com a assistência do próprio Estado, como a tendência à degradação ao meio ambiente por grandes corporações (SAAVEDRA, 2014, p. 25), dentre outros problemas da atualidade, para os quais o sistema penal não é a solução.

Apenas como menção afirma-se a incapacidade do atual modelo punitivo para atingir determinadas condutas, tendo em vista que tais ações não se coadunam com meras relações de causa e efeito, ou tampouco possuem apenas um autor determinado. Esses "novos" fatos produzem elevados danos sociais (CARLEN, 2017, p. 23), sendo, algumas vezes, previstos como condutas criminosas, mas apenadas de forma branda. Na sua grande maioria, sequer são previstos no ordenamento jurídico penal e, por diversos mecanismos de ocultamento, são ignorados por esse mesmo sistema.

Porém, quando se retoma os alvos contumazes do modelo coercitivo estatal e os danos que ele provoca, torna-se perceptível os efeitos, como o etiquetamento e a privação das capacidades a sujeitos vulneráveis, já que a atuação penal e suas penas "antes de terem um efeito reeducativo sobre o delinquente determinam na maioria dos casos, uma consolidação da identidade desviante do condenado e o seu ingresso em uma verdadeira e própria carreira criminosa" (BARATTA, 2002, p. 90).

O sistema punitivo exercido por meio do controle social tem "sancionado morte e violência, tem se revelado uma maneira de legitimar o controle e a repressão, evitando imprescindíveis questionamentos acerca das estruturas de poder" (CASTRO, 2015, p. 97). Tal controle social tem como finalidade limitar as condutas dos indivíduos em sociedade. Ocorre que este poder limitador e coercitivo está vinculado às classes sociais dominantes que possuem grande poder econômico, acesso aos meios tecnológicos da informação e comunicação, às instituições morais e religiosas, uma vez que "as classes mais poderosas utilizam esse mecanismo por meio do direito penal e de todo sistema punitivo, para consolidar um sistema de controle e dominação estrutural" (RUBIO; FRUTOS, 2013, p. 98, tradução nossa).

Seguindo esse entendimento, Zaffaroni (1991, p. 130) discorre sobre a seletividade e os estereótipos criados para os sujeitos ligados a casos criminais: "estes estereótipos permitem a catalogação dos criminosos que combinam com a imagem que corresponde à descrição fabricada, deixando de fora outros tipos de delinquentes (delinquência de colarinho branco, dourada, de trânsito, etc.)". Assim, desconsideram-se todos os crimes que não se enquadram nos seus padrões, ou seja, aqueles que têm como partes indivíduos de classes abastadas, as quais exercem grande influência no mundo dos negócios. Dessa forma, ocupantes de cargos políticos ou de valia econômica restam encobertos pela lógica de atuação do sistema penal - são, na denominação de Sutherland, os chamados criminosos de colarinho branco (SUTHERLAND, 1940, p. 1-12).

Destaca-se, neste contexto, abordagem realizada por Amaral e Rosa (2017, p. 58-60), os quais imputam que, atualmente, nos casos em que se punem autores que cometem crimes usualmente não abrangidos pela esfera penal, como infrações de natureza política e econômica, enquadradas nos crimes dos poderosos, isso não combate de nenhuma forma a desigualdade do sistema ou a sua seletividade. Justifica-se a alegação quando se expõe que tais condutas serão eventualmente penalizadas na forma de bodes expiatórios, e de modo a potencializar um espetáculo midiático que autoriza violações de garantias para proteção social, ao mesmo tempo em que novas estratégias de ocultação dessas condutas passam a ser desenhadas.

Todavia, a porta aberta da violação de direitos e garantias já está posta e será utilizada contra os mais vulneráveis. Esse é o principal engodo não percebido pela maior parte da população: o discurso de punição aos mais abastados, prolatado pelos meios de comunicação, quando eventualmente ocorre, esconde que o sistema penal é projetado para não ser aplicado facilmente sobre as condutas cometidas por grandes corporações e Estados causadores de massivos danos sociais. O que denota que a atuação midiática, ao defender a intensificação da criminalização primária (função simbólica), oculta os mecanismos (jurídicos ou de classe social) de impunidade potencializados na criminalização secundária (ANDRADE, 2012, p. 170). 
Nessa perspectiva, o controle social informal (classes sociais dominantes) executa um expressivo domínio sobre o meio dogmático, que, por resultado, atua sobre o sistema punitivo, tido como controle social formal por derivar das normas positivadas (CANTERJI, 2008, p. 99 -100). Em outras palavras, as entidades religiosas, morais e as famílias, até mesmo os meios de informação e comunicação, apesar de ocuparem espaço no controle social informal, exercem influência na atuação do controle social formal aplicado pelo Estado. Além disso, "embora o sistema penal 'formal' não seja mais do que o apêndice justificador do verdadeiro exercício de poder dos órgãos do sistema penal, a legalidade não é respeitada, nem mesmo em sua operacionalidade social" (ZAFFARONI, 1991, p. 26).

Seguindo essa lógica, a forma de criminalização dos sujeitos, primária ou secundária, demonstra já existir um perfil específico a ser criminalizado pelo poder punitivo, composto por jovens, em sua maioria negros e que possuem uma baixa renda familiar, encaixam-se no grupo social vulnerável, o que demonstra que as formas de criminalização são rotuladoras. Corroborando com isso, Carvalho (2014, p. 481) expõe que:

\begin{abstract}
Os estereótipos do 'elemento suspeito' ou da 'atitude suspeita', por exemplo, traduzem importantes mecanismos de interpretação que, no cotidiano do exercício do poder de polícia, criminalizam um grupo social vulnerável muito bem representado no sistema carcerário: jovens pobres, em sua maioria negros, que vivem nas periferias dos grandes centros urbanos.
\end{abstract}

Isto posto, observa-se uma inversão do paradigma repressivo e do consenso moral existente em relação à política de drogas no Brasil, uma vez que a rotulação e estigmatização dos sujeitos acaba desarticulando todo o processo constitucional de igualdade dos indivíduos perante a lei. Dessa forma, "as maiores chances de ser selecionado para fazer parte da 'população criminosa' aparecem, de fato, concentradas nos níveis mais baixos da escala social (sobproletariado e grupos marginais)" (BARATTA, 2002, p. 165), o que, consequentemente, acaba criando ainda mais desigualdades, isolamento social e privação das capacidades dos mais pobres, e assegurando as riquezas daqueles que já possuem status e grande poder econômico.

Demonstra-se, mais uma vez, que o sistema punitivo, assim como todas as agências que o integram, trazem uma conotação estereotipada e seletiva dos indivíduos, os quais são vítimas da perversidade das desigualdades sociais e do atual sistema excludente de punição e combate à violência. Nesse sentido, o sistema punitivo contradiz direitos humanos, os quais visam proteger o ser humano de qualquer tipo de desprezo, indiferença e de eventuais conflitos normativos, devendo ser usado como foco central para resolução de colisões, para que não se tomem decisões descabidas e com danos de difícil reparação (FLORES, 2000, p. 52), principalmente na seara penal, em que pode ocorrer a maior degeneração do indivíduo, atentando para que "a luta pela contenção da violência estrutural é a mesma luta pela afirmação dos direitos humanos" (FREITAS, 2003, p. 36).

A privação das capacitações (capabilities), contemplada a seguir, é consequência dessa arquitetura social que gera pobreza e demais formas de desigualdade e exclusão. A abordagem de Sen visa prevenir, recuperar e integrar os cidadãos de forma geral e, nesta investigação, concentra-se nas pessoas afetadas pelo atual sistema punitivo. Essa perspectiva visa à transformação das condições para tais objetivos, sendo essencial para a equidade social, a realização humana e o funcionamento da democracia.

\title{
4 O sistema punitivo brasileiro, a privação das capacitações (capabilities) e os meios de superação segundo Sen
}

As formas para a erradicação das desigualdades sociais, especialmente a pobreza, é um tema largamente debatido na contemporaneidade, bem como todos os demais impasses que ela proporciona na sociedade. Porém, na grande maioria das análises e pesquisas feitas, poucos foram os estudiosos que adentraram e esmiuçaram questões mais específicas da pobreza e o efeito que ela causa sobre os indivíduos. A herança de Sen, amplamente reconhecida nas áreas políticas, institucionais, jurídicas e acadêmicas, foi demonstrar que a pobreza, mais do que ausência de bem-estar ou renda, representa, tanto simbolicamente quanto na sua efetivação, a privação de capacitações (capabilities) humanas. Esse entendimento considera o conjunto da existência humana que está inserido no âmbito social, comunitário, 
familiar, ambiental, além de contar com os talentos individuais. Para Sen (2000, p. 109), "a pobreza deve ser vista como privação de capacidades básicas em vez de meramente baixo nível de renda, que é o critério tradicional de identificação da pobreza".

Além do fator renda, existem inúmeros elementos que acentuam essa privação, por exemplo, a idade, tendo em vista que dependendo da faixa etária de uma pessoa necessitará de mais ou menos recursos, cuidados e estruturas físicas e psicológicas, os quais carecem de uma renda elevada. Um dos exemplos é o da terceira idade, tendo em vista que essa faixa etária é uma das que mais demanda por serviços, como deslocamento e saúde, uma vez que "desvantagens como a idade, incapacidade ou doença reduzem o potencial do indivíduo para auferir renda" (SEN, 2000, p. 110).

Muitos países, como a Índia e o Brasil, passam por "[...] importantes disputas e agitações em torno de uma ampla gama de problemas que tinham sido negligenciados durante um longo período, como a corrupção, as falhas administrativas" (DRĖZE; SEN, 2015, p. 7). Nos países marginalizados, são percebidos os maiores índices de negligência praticada pelo Estado. Nesse contexto e de forma específica, temas que podem impactar na moral e na estrutura jurídica de uma sociedade desencadeiam consequências perversas, tanto para as pessoas quanto para as autoridades e os sistemas de organização política (BUDÓ, 2016). Com igual intensidade,

há também a relevante questão da suscetibilidade à corrupção que afeta sistemas específicos de administração, por meio dos quais funcionários públicos e dirigentes de empresas têm o poder de oferecer favores em troca de alguma gratificação, sem serem expostos ou penalizados por suas infrações (DRÈZE; SEN, 2015, p. 34).

Enquanto isso, o atual sistema punitivo tem se tornado apenas "uma máquina de privações", perdendo seus demais propósitos e reforçando a segregação, a seletividade e o encarceramento dos mais pobres (BARATTA, 2002, p. 161), o que não evita as desigualdades e a privação de capacidades dos cidadãos, não promovendo maior efetividade das garantias de direitos humanos e fundamentais. Por ocasião da análise do impacto desse sistema no cotidiano da vida social e nas políticas de Estado e de governo, podese afirmar, conforme Sen, quando analisa e distribuição do desenvolvimento na Índia: "enquanto algumas pessoas, em especial nas classes privilegiadas, saíram-se muito bem, tantas outras continuam a levar vidas desnecessariamente marcadas pela privação e pela precariedade" (DRĖZE; SEN, 2015, p. 9).

Portanto, os processos que geram desigualdades e pobreza também são utilizados pelo sistema penal como caracteres a definir a parcela da população mais facilmente escolhida pela atuação seletiva do sistema penal. A preocupação de Sen (2010) não se limita à vida pessoal ou aos meios para a justiça, mas destaca o seu encadeamento a fim de chamar para a superação dos reducionismos e das soluções orientadas pelo autointeresse: "os encadeamentos entre diferentes formas de liberdade são empíricos e causais, e não constitutivos e compositivos" (SEN, 2000, p. 10). A busca pela liberdade para as mais diversas formas de viver (SEN, 2011, p. 261) se interconecta com a postura criminal punitiva nacional, a qual cerceia qualquer modificação ou, no mínimo, impede escolhas amparadas em uma verdadeira liberdade.

Essa afirmativa combina-se de forma umbilical com as construções criminológicas acerca das formas de criminalização primária, secundária e terciária, ${ }^{5}$ visto que as carreiras criminosas, por assim dizer, não são meras opções de vida. Ademais, quando se observa a construção de Sen (2000, p.10) formatada a partir da necessidade de as políticas de desenvolvimento terem a expansão da liberdade como seu principal meio e fim (afastando-se das recorrentes análises com base, exclusivamente, no Produto Interno Bruto e outras formas de valoração econômica), pode-se inferir que as pessoas selecionadas discriminatoriamente pelo sistema penal são alvo de tantas privações de liberdade porque sequer possuem as bases necessárias para a tomada de decisão livre e consciente (SEN, 2000, p. 23-25). Da mesma forma, pode-se afirmar que essa exclusão impede o exercício inicial de argumentação e expressão da vontade individual e as demais necessidades básicas.

A criminalização primária encontra-se ligada ao processo de definição legislativa das condutas desviantes, e quando isso se concretiza a nível das agências de controle penal, desde a polícia ao Judiciário, encontra-se a criminalização secundária. Por fim a criminalização terciária se encontra nas consequências negativas advindas da atuação das agências sobre o indivíduo, incluindo-se inclusive os efeitos do cárcere. 
A percepção do valor moral substantivo da liberdade, segundo assevera Sen (2000) no conjunto da sua obra, demanda as condições concretas para tal, não limitando o valor da liberdade a um princípio ou concepção política, econômica ou filosófica. No sistema penal, o direito à ampla defesa (processo justo), em caso de aprisionamento, estende-se às condições de dignidade e respeito aos direitos humanos. $A$ conjugação de liberdades individuais, ${ }^{6}$ instrumentais ${ }^{7}$ e substantivas ${ }^{8}$ adquire, nesse momento, um caráter de clamor moral e político insubstituível.

Igualmente, as reflexões éticas da liberdade realizadas por Sen (2000) descontroem a "escolha" de vida criminosa, já que o número excessivo de vulnerabilidades criadas para determinados indivíduos impede o real uso da liberdade decisória sobre seu modo de vida. Nesse sentido, é imprescindível compreender que essa ausência que se antecipa aos atos definidos como desviantes, e que se prolonga posteriormente, impede a atuação do indivíduo na condição de agente, ${ }^{9}$ pois, para tal, o indivíduo deveria ter as suas liberdades efetivadas, ser um membro ativo na sociedade e realizar os seus mais diversos objetivos (econômicos, sociais e políticos).

Dessa forma, apregoa-se que as privações executadas pelo Estado, corroboradas por um sistema penal seletivo - contra classes sociais pobres e indivíduos vulneráveis por questões diversas (gênero, raça, etc.) -, geram encarceramento em massa e provocam danos ao desenvolvimento humano, não apenas individualmente, como globalmente. Ainda, averigua-se que essa postura punitiva oculta crimes de classes dominantes, formatando um modelo de atuação injusta e desigual.

[...] o fato de que o direito penal tende a privilegiar os interesses das classes dominantes, e a imunizar do processo de criminalização comportamentos socialmente danosos típicos dos indivíduos a elas pertencentes, ligados funcionalmente à existência da acumulação capitalista, e tende a digerir o processo de criminalização, principalmente, para formas de desvio típicas das classes subalternas (BARATTA, 2002, p. 165).

Os países marginalizados apresentam uma justiça baseada nas classes sociais, uma vez que os crimes praticados por classes dominantes e dirigentes ficam encobertos, como no caso de crimes ligados à violação e dilapidação do patrimônio público. De acordo com Sutherland (1940, p. 1-2), esses tipos de danos são denominados como crimes de colarinho branco por serem cometidos por indivíduos que possuem status social em razão do ofício exercido.

Em relação à invisibilidade dos crimes de sujeitos detentores de poder, Barak (2015, p. 105) examina que:

Essas contradições da legalidade burguesa são parte integrante da formação de capital e das atividades associadas que tornaram essas violações ideologicamente normativas ou culturalmente aceitáveis. Em outras palavras, os crimes dos poderosos se referem às transgressões que simplesmente normalizam a vitimização com 'os custos de fazer negócios' com 'danos colaterais'.

Entretanto, quando se trata de infrações cometidas por grupos que já possuem um estereótipo formado de "mau cidadão", como o negro, pobre e morador de favela, o clamor é muito maior, pois recebem influências sensacionalistas dos meios de comunicação (ZAFFARONI, 2012, p. 307) e de autoridades políticas, com interesses não declarados.

6 "A liberdade individual é essencialmente um produto social, e existe uma relação de mão dupla entre (1) as disposições sociais que visam expandir as liberdades individuais e (2) o uso das liberdades individuais não só para melhorar a vida de cada um, mas também para tornar as disposições sociais mais apropriadas e eficazes" (SEN, 2000, p. 46).

$7 \quad$ 'Cinco tipos de liberdade vistos de uma perspectiva 'instrumental', são investigados particularmente nos estudos empíricos a seguir. São eles: (1) liberdades políticas, (2) facilidades econômicas, (3) oportunidades sociais, (4) garantias de transparência e (5) segurança protetora" (SEN, 2000, p. 25).

8 "Às vezes a ausência de liberdades substantivas relaciona-se diretamente com a pobreza econômica, que rouba das pessoas a liberdade de saciar a fome, de obter uma nutrição satisfatória ou remédios para doenças tratáveis, a oportunidade de vestir-se ou morar de modo apropriado, de ter acesso à água tratada ou saneamento básico. Em outros casos, a privação de liberdade vincula-se estreitamente à carência de serviços públicos e assistência social, [...]. Em outros casos, a violação da liberdade resulta diretamente de uma negação das liberdades políticas e civis por regimes autoritários e de restrições impostas à liberdade de participar da vida social, política e econômica da comunidade" (SEN, 2000, p. 18).

9 "A condição de agente de uma pessoa refere-se à realização dos objetivos e valores que ela tem razão para buscar, estejam eles conectados ou não ao seu próprio bem-estar. Uma pessoa como agente não necessita ser guiada apenas por seu próprio bem-estar, e a realização da condição de agente, refere-se ao seu êxito na busca da totalidade de seus objetivos e finalidades ponderados (considered)" (SEN, 2001, p. 103). 
Nessa acepção, compreende-se com mais acuidade a visão de desenvolvimento proposta por Sen (2000) e a necessidade de atacar esses processos de privação das capacidades (capabilities), sabendo que a pobreza é apenas uma das vulnerabilidades: "o processo de desenvolvimento, quando julgado pela ampliação da liberdade humana, precisa incluir a eliminação da privação dessa pessoa" (SEN, 2000, p. 53). Outrossim, isso não pode conduzir ao retorno dos históricos equívocos criminológicos de associar as condições de renda ao cometimento de condutas desviantes, ignorando todos os demais fatores supramencionados.

Culturalmente, o desenvolvimento das sociedades tornou-se algo totalmente seletivo, que priva as capacidades dos pobres para que continuem pobres e privilegia os interesses dos mais ricos. Especificamente o sistema penal, por intermédio de um sistema punitivo e seletivo, emprega mais violência sobre os grupos sociais mais vulneráveis da sociedade, o retrato da exclusão e suas consequências em sociedades complexas, desiguais e democraticamente imaturas, como a brasileira. Sen (2000, p. 118) destaca: "durante um longo tempo, o Brasil combinou crescimento econômico acelerado com governo repressivo, enorme desigualdade e privação endêmica".

Quanto mais rico for o país e a comunidade em que se vive, mais o indivíduo terá que desenvolver suas capacidades (capabilities), pois nesses ambientes as exigências são maiores para que se possa ter uma boa aceitação, recepção e participação social, de modo que subtende-se que será necessário cumprir alguns padrões, como ter utensílios, dispositivos e ferramentas que estejam disponíveis no mercado (SEN, 2000 , p. 112). Além disso, "os chamados mercados não só regulam cada vez mais a vida cotidiana das pessoas, mas também ditam as políticas de recortes sobre as bases de um Estado" (BERNAL et al., 2014, p. 65 , tradução nossa).

Inúmeras são as causas que levam um país ou uma comunidade à pobreza, miséria, a praticar delitos, porém o sistema punitivo não se apresenta como uma solução hábil para tais problemas, pois é mais um mecanismo de privação de capacidades (BARATTA, 2002, p. 164). Por sua vez, a compreensão de Sen (2000, p.14) demonstra que a redução das desigualdades e a da privação das capacitações (capabilities) depende de inúmeros fatores que precisam ser contemplados, dos quais a renda é apenas um critério, que deve ser analisado juntamente com os mecanismos à disposição do Estado, particularmente as políticas públicas governamentais.

Ações nas áreas de educação, saúde e projetos habitacionais também são salutares para que se possa alavancar o desenvolvimento de um país, das comunidades e de seus cidadãos, assim como os investimentos visando futuras gerações e suas necessidades básicas (DRĖZE; SEN, 2015, p. 35). Um dos grandes problemas dos países e das comunidades que sofrem com a pobreza, a marginalização e as incapacidades é a falta de investimentos do Estado em direitos básicos da população. Dessa forma, perpetuam-se ou ampliam-se as desigualdades que agravam as privações de capacitações (capabilities), acarretando menores possibilidades de emprego, liberdade e qualidade de vida.

Destarte, "há provas abundantes de que o desemprego tem efeitos além da perda de renda, como dano psicológico, perda de motivação para o trabalho, perda de habilidade e autoconfiança" (SEN, 2000, p. 117). A pobreza e a privação de capacitações (capabilities) não podem ser focadas somente como detrimento da renda, visto que doenças, perturbação nas relações familiares, exclusões sociais, racismo e discriminações sexuais também causam incapacidades e o sistema punitivo não pode ser concebido como o instrumento capaz de solucionar demandas graves e estruturais como as mencionadas.

Posto isto, de forma objetiva pode-se considerar que a redução das desigualdades que estão na origem de fenômenos como a privação das capacitações (capabilities), que impossibilitam o exercício da condição de agente dos brasileiros, precisa ser enfrentada pela disposição da população e pela atuação firme do Estado por meio de políticas públicas enquanto instrumentos de efetivação de apoio e garantia de liberdade. ${ }^{10}$ Essas liberdades, quando bem integradas política e economicamente, podem ser escalonadas como fundamentais para o desenvolvimento por meio do esclarecimento, da educação e da efetivação dos

10 Para uma melhor compreensão da responsabilidade dos indivíduos, do Estado e dos governantes, assim como a importância de políticas públicas bem estruturadas, sugere-se consultar (SEN, 2000, p. 170). 
direitos humanos e fundamentais. No caso nacional, destacam-se algumas áreas evidentemente sensíveis ao investimento em políticas públicas, como saúde, educação, segurança, empregabilidade, redistribuição de renda, reforma agrária e, especificamente, o sistema de justiça criminal, pelo seu caráter simbólico e excludente.

A atual inversão de valores que caracterizam o Estado Democrático de Direito, especialmente as desigualdades que impedem a liberdade e situam contingentes de excluídos de forma desvantajosa (SEN, 2000 , p. 144), demanda a urgente construção de referenciais que legitimem a atuação dos dirigentes e das instituições, segundo a tradição democrática e a centralidade da pessoa a sua condição de agente.

\begin{abstract}
a efetivação do ideal democrático precisa ser permeada por inúmeras ações que contribuam eficazmente para o aprimoramento da atuação do Estado, dos mecanismos de participação e do atendimento das necessidades dos seus habitantes, entre outras. As diferentes áreas do desenvolvimento (econômico, social, humano e outras) não possuem legitimidade moral quando estruturadas pelos interesses dos governos autoritários, de Estados repressivos ou de instituições que sustentam seus interesses (ZAMBAM, 2012, p. 206).
\end{abstract}

Com igual preocupação, devem-se respeitar os direitos humanos e fundamentais dos indivíduos, pois estão vinculados a todos os modelos de classes sociais, ciclos econômicos, culturais e políticos que fazem parte do meio social, os quais garantem a aplicabilidade em conformidade com as bases jurídicas de uma série de direitos e garantias basilares dos seres humanos. Trata-se de direitos como à vida, à saúde, à integridade física, à igualdade (no sentido formal e material), dentre outros elementos que objetivam a proteção do ser humano e igualmente a potencialização do seu desenvolvimento com dignidade e, especialmente aqui, com liberdade.

Afirma-se a necessidade de, em conformidade com a abordagem de Sen, efetivar o atendimento das demandas básicas da população, em especial nas áreas da saúde, educação e projetos habitacionais, visando sanar as desigualdades e múltiplas formas de violência decorrentes dessa disparidade. Um projeto social justo e sustentável está integrado à superação, com igual destemor, da violência e outras exclusões, segundo prerrogativas democráticas, especificamente com amplos mecanismos de participação e exercício da liberdade.

\title{
5 Conclusão
}

O composto de crenças e princípios comuns, criados por uma sociedade, gera um instituto denominado pela doutrina como consciência coletiva ou comum, o qual é existente desde os primórdios da humanidade. As bases dogmáticas do direito, em específico do direito penal, levam em consideração as definições criadas por esse instituto, como, por exemplo, a definição de quem é ou não criminoso, de modo que criam rótulos e estereótipos específicos de bons e maus cidadãos. Sobrevém que a consciência coletiva também recebe atuações do meio de disputas sociais e políticas, assim acrescentando hostilidade ao código moral da sociedade atinente ao sistema de intervenção punitivo.

Ocorre que, apesar do transcurso de tempo, marcas históricas no Brasil, de discriminação, desigualdades e privação de capacitações (capabilities), que alijam liberdades, ainda assolam sujeitos que são considerados como infratores de forma antecipada e, assim, "justificam-se" as ações que os violam ou eliminam tais indivíduos. Nesse sentido, o número de pessoas que têm suas liberdades violadas cresce cada vez mais dentro do sistema penal brasileiro, seja durante o cárcere, seja em intervenções policiais do cotidiano, seja por negligência do Estado, como a falta de fornecimento de medicamentos, de educação e de investimentos na área de habitação, o que ocasiona as violações de direitos e garantias fundamentais e a privação das capacitações (capabilities) e do desenvolvimento dos indivíduos, em especial daqueles já etiquetados pelos mecanismos de controle social.

Logo, esta pesquisa buscou, partindo da óptica da compreensão de sociedade sustentável, discorrer acerca da banalização da intervenção punitiva como forma de privação das capacitações (capabilities), buscando nas contribuições de Sen orientações para a superação dessa doutrina macrocriminalizadora. 
Porém, antes da abordagem específica do modelo punitivo, contextualizou-se a noção da sustentabilidade social, bem como o quanto seus objetivos estão alinhados com a melhoria nas condições de vida e com a busca pela justiça social.

Com base nisso, aplacar no segundo item a questão de banalização da intervenção punitiva a partir do atual controle social, bem como a estigmatização e marginalização dos mais pobres, torna-se um componente correspondente aos objetivos macro definidos pela sustentabilidade. No mesmo sentido, as desconstruções criminológicas denunciam a impossibilidade de manutenção de um sistema penal que agrava processos de desigualdade, pobreza e ainda intensifica violações aos direitos humanos mais básicos dos seus cidadãos.

Em seguida, no terceiro capítulo foram examinadas contribuições de Sen sobre as privações das capacitações (capabilities) dos indivíduos e como isso se relaciona com a desigualdade e a pobreza, que são fatores de seletividade do sistema punitivo. A criminalização aplicada pelo sistema penal deve ser de intervenção mínima na liberalidade individual, devendo o direito penal ser a última opção em matéria punitiva, sob pena de se tornar um direito penal inquisitivo e abusivo. Por essa razão, o atual modelo seletivo e discriminatório operado pelo sistema penal é insustentável, violando todos os direitos e garantias básicos dos seres humanos e, ao mesmo tempo, contribuindo sensivelmente com o agravamento dos processos de desigualdade social.

Ademais, ações praticadas pelo Estado e corporações também necessitam ser mais bem investigadas, pois são muitas as ações abusivas e também os atos de negligência que causam o verdadeiro genocídio dos mais pobres, uma vez que existem interesses não declarados do Estado e do mercado. Tendo em vista que a maior parte dos ocupantes da estrutura estatal é composta por indivíduos de classes sociais economicamente dominantes, os objetivos do poder público tornaram-se os objetivos destes. Em vista disso, a acumulação e a privatização de bens tornaram-se uma prática reiterada dos governos atuais, retirando o fornecimento de serviços básicos do alcance dos mais vulneráveis e cerceando a liberdade de escolha dessas pessoas, efetivando a verdadeira privação das capacidades dos mais pobres e impedindo o alcance da sua condição de agente.

De acordo com sem, as modificações e possíveis soluções desse sistema seriam começar pelo investimento nas necessidades básicas da população (por meio de políticas públicas), em especial saúde, educação e projetos habitacionais, para que se consiga diminuir as desigualdades, violências e preconceitos aos poucos, os quais não serão resolvidos por intermédio de um sistema punitivo seletivo, conforme demonstrado. Embora a busca por um sistema de justiça criminal mais justo seja também uma meta para garantia e segurança das liberdades delineadas pelo autor, reserva-se a reflexão sobre a real necessidade de manutenção de um sistema que intensifica desigualdades e incapacita seres humanos para a órbita criminológica.

Diante do exposto, a principal contribuição de Sen está na sua abordagem eticamente orientada à sustentabilidade social e que, junto aos fundamentos criminológicos, oferece tanto instrumentos de desconstrução dessas instituições violadoras quanto alternativas na busca por uma sociedade mais justa e sustentável, inclusive do ponto de vista criminal, a fim de ampliar o exercício das liberdades em vista de um modelo sustentável de desenvolvimento.

\section{Referências}

AMARAL, Augusto Jobim do; ROSA, Alexandre Morais da. Cultura da punição: a ostentação do horror. 3. ed. Florianópolis: Empório do Direito, 2017.

ANDRADE, Vera Regina Pereira de. Pelas mãos da criminologia: o controle penal para além da (des) ilusão. Rio de Janeiro: Revan, 2012.

BARAK, Gregg. The crimes of the powerful and the globalization of crime. Revista Brasileira de Direito, Passo Fundo, v. 11, n. 2, p.104-114, jul.-dez. 2015. 
BARATTA, Alessandro. Criminologia crítica e crítica do direito penal. 3. ed. Rio de Janeiro: Revan: ICC, 2002.

BERNAL, Camilo Ernesto; CABEZAS, Sebastián; FORERO, Alejandro; RIVERA, Iñaki; VIDAL, Iván. Más allá de la Criminologia. Un debate epistemológico sobre el daño social, los crímenes internacionales y los delitos de los mercados. In: RIVERA, Iñaki (coord.). Delitos de los Estados, de los mercados y daño social. Barcelona: Anthropos, 2014. p. 35-80.

BOFF, Leonardo. A terra na palma da mão: uma nova visão do planeta e da humanidade. Petrópolis: Vozes, 2016.

BOFF, Leonardo. Sustentabilidade: o que é - o que não é. 4. ed. Petrópolis: Vozes, 2015.

BRASIL. Ministério da Justiça e Segurança Pública. Levantamento Nacional de Informações

Penitenciárias - INFOPEN. Brasília, jun. 2016. Disponível em: http://depen.gov.br/DEPEN/depen/ sisdepen/infopen/relatorios-sinteticos/relatorio_2016_2211.pdf. Acesso em: 09 set. 2018.

BUDÓ, Marília de Nardin. Danos silenciados: a banalidade do mal no discurso científico sobre o amianto. Revista Brasileira de Direito, Passo Fundo, v. 12, n. 1, p. 127-140, jan.-jun. 2016.

CANTERJI, Rafael Braude. Política criminal e direitos humanos. Porto Alegre: Livraria do Advogado, 2008.

CARLEN, Pat. Criminologias alternativas. In: CARLEN, Pat; FRANÇA, Leandro Ayres (org.).

Criminologias alternativas. Porto Alegre: Canal Ciências Criminais, 2017. p. 19-34.

CASTRO, Fernando Borba de. Justiça restaurativa: um olhar para além da repressão. Florianópolis: Empório do Direito, 2015.

CARVALHO, Salo. Nas trincheiras de uma política criminal com derramamento de sangue: depoimento sobre os danos direitos e colaterais provocados pela guerra às drogas. In: CARVALHO, Salo de (org.). A política criminal de drogas no Brasil (estudo criminológico e dogmático da Lei 11.343/06). 7. ed. São Paulo: Saraiva, 2014. p. 477-495.

CARVALHO, Salo; DUARTE, Evandro Piza. Criminologia do preconceito: racismo e homofobia nas Ciências Criminais. São Paulo: Saraiva, 2017.

COLANTONIO, Andrea. Social sustainability: a review and critique of traditional versus emerging themes and assessment methods. Loughborough: Loughborough University, 2009.

DRĖZE, Jean; SEN, Amartya. Glória incerta: a Índia e suas contradições. Tradução de Ricardo Doninelli Mendes, Laila Coutinho. São Paulo: Companhia das Letras, 2015.

ELKINGTON, John. Cannibals with forks: the triple bottom line of 21 st century business. Stony Creek, Conn.: New Society Publishers, 1998.

FLAUZINA, Ana Luiza Pinheiro. Corpo negro caído no chão: o sistema penal e o projeto genocida do estado brasileiro. Brasília, DF, 2006. Dissertação (Mestrado em Direito). Universidade de Brasília, Brasília, 2006. Disponível em: http://repositorio.unb.br/bitstream/10482/5117/1/2006_ AnaLuizaPinheiroFlauzina.pdf. Acesso em: 10 abr. 2018.

FREITAS, Ricardo de Brito A. P. As razões do positivismo penal no Brasil. São Paulo: Juarez de Oliveira, 2003.

GIAMBERARDINO, André Ribeiro. Crítica da pena e justiça restaurativa: a censura para além da punição. Florianópolis: Empório do Direito, 2015.

HERRERA FLORES, Joaquín. Hacia una visíon compleja de los derechos humanos. In: HERRERA FLORES, Joaquín (org.). El vuelo de anteo: derechos humanos y crítica de la razón liberal. Bilbao: Desclée, 2000. p. 19-78.

INSTITUTO BRASILEIRO DE GEOGRAFIA E ESTATÍSTICA. Estatísticas sociais. Brasília, 2018. Disponivel em: https://ww2.ibge.gov.br/home/estatistica/pesquisas/pesquisa_resultados.php?id_ pesquisa=125. Acesso em: 09 set. 2018. 
JAKOBS, Günther; MELIÁ, Manuel Cancio. Direito penal do inimigo: noções e crítica. São Paulo: Livraria do Advogado, 2012.

LATOUCHE, Serge. La sociedade de la abundancia frugal. Barcelona: Icaria: Antrazyt, 2011.

MCKENZIE, Stephen. Social sustainability: towards some definitions. Magill: Hawke Research Institute: University of South Australia, 2004. (Working Paper Series, 27).

MORIN, Edgar. A via para o futuro da humanidade. 2. ed. Rio de Janeiro: Bertrand Brasil, 2015.

NASCIMENTO, Elimar Pinheiro do. Trajetória da sustentabilidade: do ambiental ao social, do social ao econômico. Estudos avançados, São Paulo, v. 26, n. 74, p. 51-64, 2012.

OXFAM. Compensem o trabalho, não a riqueza. Reino Unido: Oxfam, 2018.

RUBIO, David Sánchez; FRUTOS, Juan Antonio Senent de. Teoria crítica del derecho: nuevos horizontes. Sevilla: Centro de Estudios Jurídicos y Sociales Mispat, A.C., 2013.

SAAVEDRA, Jaime Fernando Estenssoro. História do debate ambiental na política mundial 19451992: a perspectiva latino-americana. Tradução de Daniel Rubens Censi. ljuí: Editora da UNIJUÍ, 2014.

SEN, Amartya. A ideia de justiça. São Paulo: Companhia das Letras, 2011.

SEN, Amartya. Desenvolvimento como liberdade. Tradução de Laura Teixeira Motta. São Paulo: Companhia de letras, 2000.

SEN, Amartya. Desigualdade reexaminada. Tradução de Ricardo Doninelli Mendes. Rio de Janeiro: Record, 2001.

SUTHERLAND, Edwin H. White collar criminality. American Sociological Review, Washington, v. 5, n. 1, p. 1-12, Feb. 1940. Disponível em: http://www.jstor.org/stable/2083937. Acesso em: 02 jun. 2018.

ZAFFARONI, Eugenio Raúl. A palavra dos mortos: conferências de criminologia cautelar. São Paulo: Saraiva, 2012.

ZAFFARONI, Eugenio Raúl. Em busca das penas perdidas: a perda de legitimidade do sistema penal. Rio de Janeiro: Revan, 1991.

ZAFFARONI, Eugenio Raúl; PIERANGELI, José Henrique. Manual de direito penal brasileiro: parte geral. 8. ed. São Paulo: Revista dos Tribunais, 2010.

ZAMBAM, Neuro José. Amartya Sen: liberdade, justiça e desenvolvimento sustentável. Passo Fundo: IMED, 2012.

Recebido em: 24/09/2018

Aprovado em: 08/02/2019 